\title{
Traditional and Digital Representations of Atmosphere in Architecture. A first systematisation
}

\author{
Danilo Di Mascio ${ }^{1, *}$ and Yvette Putra ${ }^{2}$ \\ ${ }^{1}$ Department of Architecture and 3D Design, School of Art, Design \& Architecture, The University of \\ Huddersfield, United Kingdom \\ ${ }^{2}$ Melbourne School of Design, Faculty of Architecture, Building \& Planning, University of Melbourne, \\ Melbourne, Australia
}

\begin{abstract}
In architecture, atmosphere and its many implications have, in recent years, received increased attention. This paper considers atmosphere in architectural representation, and begins with an exploration of different definitions of these atmospheric representations. This paper then identifies and summarises representations of atmosphere in architecture and their key aspects, and proposes, in the form of a timeline, a preliminary systematisation of these aspects. This paper considers both traditional and digital representations of atmosphere in architecture, and focuses on aesthetic and emotional qualities of atmosphere. Thus, this paper is not limited to realistic and scientific approaches of atmosphere as meteorological conditions, but extends to atmosphere as emotions and mood. This paper also suggests cross-fertilisation, in the representation of atmosphere, between architecture and other fields. Therefore, while this paper explores atmospheric representations in architecture, it establishes its discussions by crossing disciplinary boundaries. It is anticipated that this paper will encourage further research, including recommendations for negotiating the apparent incompatibility of traditional and digital representations, to maintain qualities characterising well-known examples from the past.
\end{abstract}

\section{Introduction}

This paper considers atmosphere in architectural representation, and begins with an exploration of different definitions of these atmospheric representations. This paper then identifies and summarises key aspects relevant to representing atmosphere in architecture, and proposes, in the form of a timeline, a preliminary systematisation of these aspects.

In architecture, atmosphere and its many implications have, in recent years, received increased attention. The word 'atmosphere' offers several interpretations, as it is linked to a number of concepts. These concepts range from objective meteorological conditions to more subjective moods, in which the latter are prompted by tangible and intangible characteristics of buildings and places.

\footnotetext{
* Corresponding author: D.DiMascio@hud.ac.uk
} 
There is a great deal of research around the meaning and concepts of atmosphere in architecture, with most of these works investigating atmosphere relative to real-world buildings and places [1]. In contrast, there is a lack of scientific study exploring atmosphere in architectural representation.

Atmosphere in architectural representation is particularly relevant in the present, when considerations for architecture's functional and quantitative aspects appear to have overtaken considerations for its qualitative aspects. In terms of atmosphere in architectural representation, its qualitative aspects include emotions, triggered by architecture and architecture's attendant characteristics.

Architecture is one of many disciplines contributing to atmosphere creation. For centuries, representational techniques and tools have been used to depict and interrogate atmosphere in architecture. Yet, despite the significance of atmosphere in architecture, there appears to be no known critical investigation or systematisation of atmospheric representations in architecture.

This paper considers both traditional and digital representations of atmosphere in architecture. It focuses on aesthetic and emotional qualities of atmosphere, as suggested by Zumthor in Atmospheres: "We perceive atmosphere through our emotional sensibility [...] We are capable of immediate appreciation, of a spontaneous emotional response, of rejecting things in a flash. That is very different from linear thought" [2] $]^{\dagger}$. Thus, this paper is not limited to realistic and scientific approaches of atmosphere as meteorological conditions, but extends to atmosphere as emotions and mood.

\section{Methodology}

A methodology of four main steps has been used to systematise traditional and digital representations of atmosphere in architecture, and their key aspects (Fig. 1). These steps constitute this paper's main structure.

This paper begins with a brief analysis of definitions of atmosphere in architecture. As 'atmosphere' carries different meanings, it is critical to explore its origins and different interpretations, and consider how they support this research. This paper then examines atmosphere's role in representation, by establishing the role's importance and highlighting two possibilities for representing atmosphere. This paper's subsequent section describes the techniques and content of atmospheric representations, both historically and in the present. The final section proposes, through a timeline, a first visual systematisation of atmospheric representation in architecture, and key aspects of these representations.

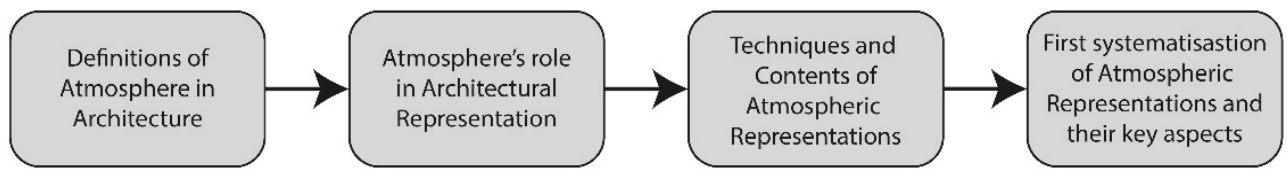

Fig. 1. Main methodological steps to systematise traditional and digital representations of atmosphere in architecture, and their key aspects.

$\dagger^{\dagger}$ (Zumthor 2006: 13) 


\section{Definitions of Atmosphere}

The word 'atmosphere' has its origins in the mid-seventeenth century, from the modern Latin atmosphaera, and from the Greek atmos, meaning 'vapour', and sphaira, meaning 'ball' or 'globe' [3]. Earliest attestations of the word describe gaseous envelopes around, most commonly, the Earth and other heavenly bodies: "That there is an Atmo-sphaera, or an orbe of grosse vaporous aire, immediately encompassing the body of the Moone." Over time, atmosphere's meaning extended to "mental and moral environment", "pervading tone or mood", and even "fascinating or beguiling associations or effects".

For the meanings "layers of gas surrounding a planet" and "spatial ambience and mood", Vignjević uses the shorthand "meteorological notion" (or "technical notion") and "aesthetic notion" respectively [4]. Yet, the distinction between these two positions is not altogether clear. This is seen, for instance, in how mood is affected by weather, which is an established correlation in psychology [5-6]. In the context of architectural representation, Wigley expresses this connection thus: "The weather conditions represented in traditional drawings have always contributed greatly to the mood of the project" [7]".

To return to atmosphere's semantics, Ford suggests that the interdependence of its two definitions is traceable to the late seventeenth and early eighteenth centuries [8]. This coincides with Romanticism's flourishing, when "atmosphere was used both to articulate the divergent autonomous forms taken by the poetic imagination and scientific disciplines, but also to mediate their continued communication" [8] ${ }^{\S}$. Such practices are evident in the era's literary and visual arts, and, as this paper discusses later, constitute a shift in Western aesthetics.

Current architectural discourse reflects the challenges of atmosphere's definitions. According to Wigley, atmosphere "is some kind of sensuous emission of sound, light, heat, smell, and moisture", but is, at the same time, "a swirling climate of intangible effects" [7]"*

In representation, there is an unclassifiable variety of contexts and media. As such, each of atmosphere's definitions shows a likewise extreme variety of iterations in its representations. But, as representations of meteorological phenomena must be recognised by viewers, they are necessarily limited by widely accepted conceptions of how such phenomena appear. On the other hand, representations of tone, mood, and effect are more complex. This is because their meanings are inherently subjective, and, therefore, more varied. This paper acknowledges atmosphere's dual meanings, yet underscores the meanings' inseparability. In subsequent sections, this paper does not make any distinction between these meanings.

\section{The Role of Atmosphere in Representation}

The first possibility of atmospheric representation is 'literal'. In literal representations, viewers are, either through realism or suggestion, drawn into visualised worlds. The main aim of literal representations is to increase the viewers' direct involvement with these representations, in which viewers are either participants or spectators in specific moments. The viewers' involvement with a precise moment is, as Bois writes of perspectives, "the

\$(Wigley 1998: 19)

$\S$ (Ford 2018: 5)

*** (Wigley 1998: 18) 
petrification of the spectator, similar to the Medusa's head" [9] $]^{\dagger \dagger}$. Meanwhile, the potential for viewers' immersion is described by Deleuze in this way: "As a spectator, I experience the sensation only by entering the painting, by reaching a unity of the sensing and the sensed" $[10]^{\mathrm{H}}$.

The second possibility in representing atmosphere is 'symbolic', in which symbolic representations function largely to convince viewers of particular ideas. Symbolic representations include iconography and allegory [11]. In symbolic representations, the sky may suggest universal order, and a tree may link the celestial and terrestrial spheres. Symbolic representations require their viewers to grasp their symbols, so these representations encourage less immediate immersion than literal representations.

Across both literal and symbolic representations, atmosphere is used to increase the viewers' emotional engagement, and to, ultimately, evoke emotions such as admiration, curiosity, and wonder. Emotional qualities of atmospheric representation are described in a note, in Powell and Leatherbarrow's Masterpieces of Architectural Drawings, about Piranesi's 'Prisons' (1745-50): "The nightmare emotions [...] were transformed into a visual aesthetic experience through pictorial means" $[12]^{\S \S}$. Powell and Leatherbarrow then mention how Piranesi's use of double diagonal perspective evokes "a feeling [...] of immensity" [ibid.]. These descriptions support that representations of atmosphere in architecture are, primarily, to elicit emotions, and, accordingly, to allow viewers to experience certain moments.

In architectural representation, emotions were particularly emphasised in the Picturesque, an English aesthetic category of the eighteenth century [13] $]^{* * *}$. In the Picturesque, there was a preference for architecture which was "more visual than intellectual", leading to "architectural drawings less geometrical and abstract and more concerned with colour, light and atmosphere than they had ever been before" [ibid.].

\section{Techniques and Content of Atmospheric Representations}

This section examines, through an analysis of selected works, some of the main techniques and content of atmospheric representations in architecture. This research recognises the interconnectedness of architecture and other fields, so the selected examples are not limited to those produced in an architectural context. These examples have been chosen chiefly for their frequent references in the literature. This section begins with a discussion of historical representations of atmosphere, before focusing on more current examples.

\subsection{Historical representations}

Shifts in atmospheric representation over time are evinced in historical architectural representations. This is seen in works of Piranesi (1720-78), Boullée (1728-99), Gandy (1771-1843), Ruskin (1819-1900), Garas (1866-1925), and Ferriss (1889-1962). In Gandy's 'Architectural Ruins, a Vision' (1798) (Fig. 2 - left), atmosphere is conveyed both literally and symbolically. The rotunda at the Bank of England, although completed the same year as this painting, is depicted as a ruin. It is illuminated by sunlight in an overcast sky, conveying

\footnotetext{
† (Bois 1981: 46)

H (Deleuze 2004: 25)

$\S \S$ (Powell and Leatherbarrow 1982: 35)

*** (Curl \& Wilson 2015: 578)
} 
decline but leaving traces of hope for the future. Garas' 'Artist's Interior' series (1896) comprises imaginative views which "strive to express ideas, sensations or musical rhythms in architecture" [14] ${ }^{\dagger \dagger}$. This series, much like van Gogh's 'Café Terrace at Night' (1888), demonstrates how intimate scenes communicate evocative atmospheres.

In art, examples of atmospheric representations of architecture are found in works of Romanticism, such as those by Turner (1775-1852), and Impressionism, such as those by Monet (1840-1926). In the 'Rouen Cathedral' series (c. 1892-94) and 'Houses of Parliament' series (c. 1899-1901), Monet investigated and represented changing light conditions, and qualities of light itself on architecture. These series show how light influences the atmosphere of their architectural subjects. The overall effect is more literal than symbolic, as viewers find themselves caught in exact moments of architectural and climactic collision. In identifying representations of atmosphere in art, it is necessary to also mention occasional earlier proponents such as Claude (1600-82). Claude's use of light, typically in expanses of sky and over bodies of water, communicates idealised places, as seen in 'The Embarkation of the Queen of Sheba' (1648) (Fig. 2 - right).

These examples allow for the identification of elements characteristic of representations of atmosphere, such as strategic use of points of view, and depictions of light and shadow. Architectural aspects, such as shape and composition, can be included as important components of some atmospheric representations. Further, this historical survey establishes a framework for discussing the current state-of-play of atmospheric representation, in which digital technologies appear to have all but superseded traditional methods of representation.
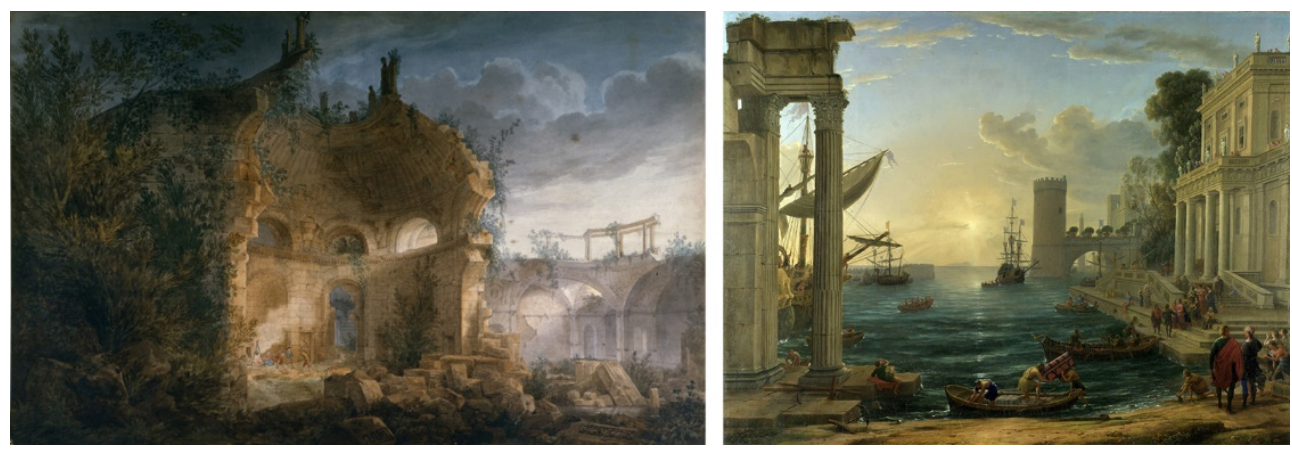

Fig. 2. (left) Joseph Michael Gandy, “Architectural Ruins, a Vision” (1798) (Source: Photo $@$ Sir John Soane's Museum, London); (right) Claude Lorrain "The Embarkation of the Queen of Sheba" (1648) (Source: Image (C) The National Gallery, London 2019).

††' (Mathieu 2003: 64) 


\subsection{Modern and contemporary representations}

The analysis of drawings in 100 Years of Architectural Drawings, 1900-2000 [15] demonstrates that World War II, and the ensuing Modern movement, precipitated an important change in the style and content of architectural representation. Representations of the preceding generation are more imaginative, and show influences from artistic movements such as Romanticism, Futurism, and Expressionism. Modern representations, in contrast, show greater simplicity and functionality. Typical drawings of the Modern period have clearer line-work, with light and shadow almost absent. + Modern representations are, it may be suggested, often as functional and aseptic as the buildings and spaces they represent. These representations usually do not depict light and shadow in any Expressionist manner. However, there are some exceptions from the Modern era, with architects whose representations display atmospheric qualities akin to those in historical examples. Wright (1867-1959) and Kahn (1901-74) were two such Modernists, with Wright's rendering of Fallingwater (1935) described as having a sky "drawn as a series of parallel wavy blue lines that echo the shape of the building and trees. It appears to be an atmospheric aura produced by the design." [ [7] $\S \S$

垜 The collages of Alison (1928-93) and Peter Smithson (1923-2003), for the Golden Lane Estate competition entry (1953), are prominent examples of this.

$\$ \S$ (Wigley 1998: 20) 

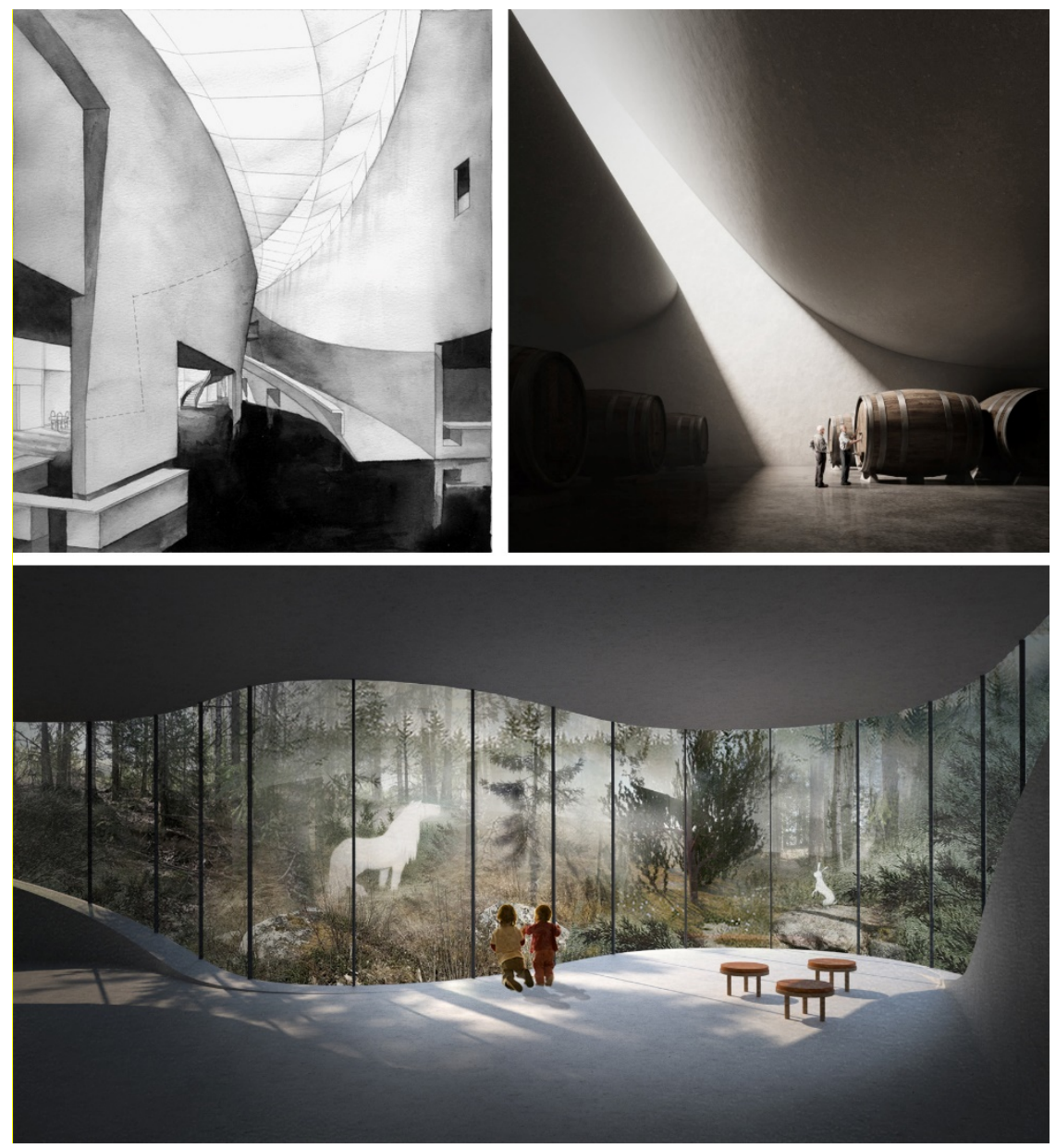

Fig. 3. (top left) View of the foyer of the Kiasma Museum by Stephen Holl (1993. Source: C) Steven Holl); (top right) View by Darcstudio of Pingus Winery by Peter Zumthor (2018. Source: (C) Darcstudio); (bottom) View of the National Center for Theodor Kittelsen by Snøhetta (2017. Source: (C) Snøhetta).

At present, one of the main objectives of digital visualisations in architecture is, arguably, to market projects to clients and other parties. Again, however, there are exceptions to this condition, as in works of architects and practices such as Holl (b. 1947) (Fig. 3 - top right), Zumthor (b. 1943) (Fig. 3 - top left), and Snøhetta (Fig. 3 - bottom). Holl's restrained use of traditional media draws viewers into atmospheres of contemplation and controlled movement. Zumthor's design is represented more vividly, to convince viewers of the space's illuminative, material, and scalar possibilities, and of the moods which follow. Snøhetta's vision of an interior at the National Center for Theodor Kittelsen communicates, through its view towards the adjacent forest, a feeling of discovery and wonder. This is, more precisely, represented in two children looking out at an 'enchanted' view, reminiscent of Kittelsen's drawings and in an apparent homage. Here, the window opens onto a real landscape depicted fantastically, emphasised further by the light's ephemerality and the presence of two faintly rendered animals.

For most of history, representations of atmosphere in architecture have been largely visual through, for example, painting and film. In these instances, viewers occupy a relatively 
passive role. But with the advent of virtual reality and related technologies, atmospheric representations increasingly include the other senses.

\section{A First Systematisation}

A timeline, spanning the seventeenth century until today, may be established with examples from this paper's previous sections and elsewhere. This timeline provides a first visual systematisation of traditional and digital representations of atmosphere, in architecture and related fields. This diagram (Fig. 4.) shows a portion of this timeline, including the examples' titles, along with names of their authors (such as architects or artists), and key aspects defining the examples' atmospheric qualities. Each coloured line suggests a different visual art such as painting, film, and video games. This timeline, as it appears below, overviews some of the main examples. It may be further developed with more examples, for more complex analyses. This systematisation allows for reflections on different representations of atmosphere.

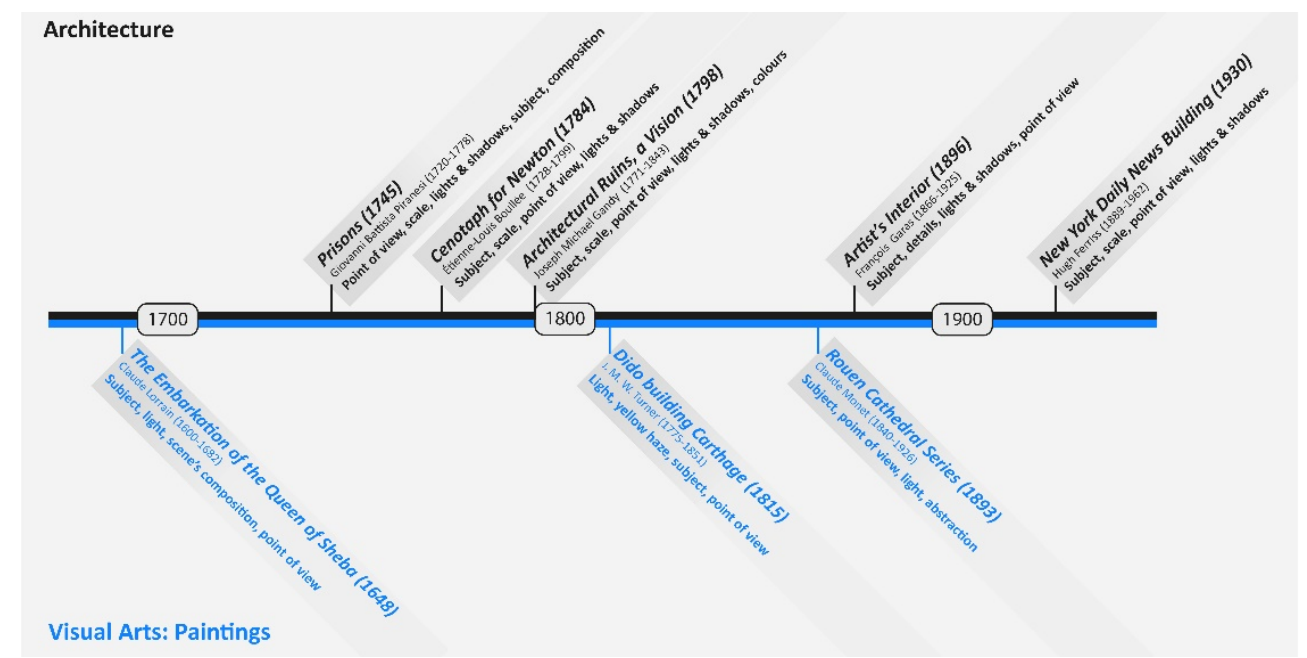

Fig. 4. A portion of the timeline showing the examples' titles, authors, and key aspects defining the examples' atmospheric qualities.

\section{Conclusion and Future Developments}

This paper identifies and describes traditional and digital representations of atmosphere in architecture, and their key aspects, and proposes their first visual systematisation. This systematisation is achieved through a timeline, in which a line indicating architecture is matched with lines indicating painting, film, video games, and other visual arts. In this way, this paper suggests cross-fertilisation, in the representation of atmosphere, between architecture and other fields. Therefore, while this paper explores atmospheric representations in architecture, it establishes its discussions by crossing disciplinary boundaries.

It is anticipated that this paper will encourage further research, including recommendations for negotiating the apparent incompatibility of traditional and digital representations, to maintain qualities characterising well-known examples from the past. 
Atmosphere is an essential element of architecture. With the growing orientation towards architecture's quantitative aspects, this paper proposes that atmosphere, as a subject of discussion, will, paradoxically, find greater relevance.

The authors wish to thank Steven Holl Architects (www.stevenholl.com), Snøhetta (https://snohetta.com/), and Darcstudio (http://darcstudio.co.uk/), for granting permission to include their images in this paper.

\section{References}

1. G. Böhme, C. Borch, Architectural atmospheres: On the experience and politics of architecture (Birkhäuser, Basel, 2014)

2. P. Zumthor, Atmospheres (Birkhäuser, Basel, 2006)

3. OED Online, <www.oed.com/viewdictionaryentry/Entry/12552>

4. A. Vignjević, AM Journal 0 (2017)

5. E. Howarth, M.S. Hoffman, British Journal of Psychology, 75 (1984)

6. M.C. Keller, et al., Psychological Science, 16 (2005)

7. M. Wigley, Daidalos, 68 (1998)

8. T. H. Ford, Wordsworth and the poetics of air (Cambridge University, Cambridge, 2018)

9. Y.-A. Bois, Daidalos, 1 (1981)

10. G. Deleuze, Francis Bacon (University of Minnesota, Minneapolis, 2005)

11. M. Battistini, Symbols and allegories in art (J. Paul Getty Museum, Los Angeles, 2005)

12. H. Powell, D. Leatherbarrow, Masterpieces of architectural drawing (Orbis, London, 1982)

13. J.S. Curl, S. Wilson, The Oxford dictionary of architecture (Oxford University, Oxford, 2015)

14. C. Mathieu, Orsay architecture (Paris: Editions Scala, Paris, 2003)

15. N. Bingham, 100 years of architectural drawing, 1900-2000 (Laurence King, London, 2013) 